\title{
Medical and Psychological Morbidity of Patients with Urogenital Fistula
}

\author{
Pushpa Srichand ${ }^{1}$, Nabila Hassan ${ }^{2}$, Sher Shah Syed ${ }^{3}$, Gul Farheen ${ }^{1}$ \\ ${ }^{1}$ Isra University Hyderabad, Pakistan \\ ${ }^{2}$ Liaquat University of Medical \& Health Sciences, Jamshoro, Pakistan \\ ${ }^{3}$ Pakistan National Forum on Women Health, Pakistan.
}

Received: 20 October 2018; Accepted: 12 December 2018

DOI: 10.3126/njog.v13i3.23424

\begin{abstract}
Aim: This study aimed to determine the frequency of medical and psychological morbidity of patients with urogenital fistulae.

Methods: It was a descriptive study carried out at Liaquat University Hospital and Isra University Hospital, Hyderabad, Pakistan from 01/06/2007 to 30/06/2018, where 520 patients with urogenital fistulae were managed. A pre-designed proforma was used to record the details about medical and psycho-social consequences. Data was analyzed, and results were described as frequency and percentages.

Results: Among 16759 gynecological admissions, 520 (3.1\%) were confirmed cases of urinary fistulae. Average age of patients was $31 \pm 2.8$ years and average parity was $3 \pm 2.4$. Regarding health consequences, all patients had major degree depression. Majority ( $88 \%$ ) of the patients were malnourished. Severe excoriation of vulva and inner thighs was seen in $338(65 \%)$ patients. Vaginal stenosis, vaginal and vesical calculi were other medical problems. Almost all $(n=511,98 \%)$ patients were found to be socially isolated. $62 \%$ patients kept themselves restricted to home, with avoidance of family gatherings and travelling. Marital breakdown seen in $81 \%$ ( $=241$ ). $90 \%$ of patients quit their job. Majority of them suffered social, verbal or physical abuse.
\end{abstract}

Conclusions: Patients with urogenital fistulae not only havesurgical morbidity, they also do suffer from significant medical and psychosocial morbidity. There is a definite need to address these under-looked miseriesby a devoted fistulae team working in collaboration with social workers, religious leaders and healthcare providers.

Key words: fistula, psycho-social morbidity, urinary fistula.

\section{INTRODUCTION}

Vesico-vaginal fistula (VVF) is an abnormal communication between bladder and the vagina causing continuous urinary leakage in the vault of vagina. ${ }^{1}$ According to World Health Organization, around two million women in Asia,Africa and Arab get affected by obstetric fistula with added burden of 50,000 to 100,000 new casesannually. ${ }^{2}$ However, the actual figures may be underestimated as majority of the patients remain unreported due to social isolation. ${ }^{3}$ Etiology varies worldwide depending upon the availability of quality of health system. In developing countries, the predominant cause of vesico-vaginal fistula is obstetric in origin secondary to neglected obstructed labour while iatrogenic fistula observed secondary to difficult gynecological surgeries is common in industrial countries. ${ }^{4}$ A report from Nigeria estimated that 800,000 to 100,0000 cases of fistula patients are waiting for repair.5Recently, a rising trend of iatrogenic fistula is seen secondary to caesarean sections and hysterectomies often performed by unskilled surgeons. ${ }^{5}$ Irrespective of the etiology, the consequencesof urinary fistula are enormous. The continuous urinary leakage leaves a devastating effect on woman's life by affecting her personal hygiene, self-esteem, social and sexual life. ${ }^{6}$ Besides the medical consequences of this terrible illness, the magnitude of its effect over mental health is often the untouched part in management.Keeping in view the serious consequences of this illness and paucity of data on medical and psychosocial morbidity in patients with urinary fistula, this study

\section{CORRESPONDENCE}

Dr Pushpa Srichand

Department of Obstetrics and Gynecology

Isra University Hyderabad, Pakistan

Phone: +92-3008371096.

Email: pushpasrichand_sachdev@yahoo.com 
is planned. ${ }^{7}$ This will not only help us to understand the needs of a fistula patient but will also help to expand our services for early recognition,treatment with appropriate referrals in particular to psychiatric illness besides surgicaltreatment.

\section{METHODS}

This is a descriptive cross-sectional study carried out at Liaquat University Hospital and Isra University Hospital, Hyderabad, Pakistan. The centers were established in 2007 at Liaquat University of Medical and Health Sciences, Hyderabad and in 2011 at Isra University, Hyderabad. These centers are supported by Pakistan National Forum on Women's Health (PNFWH) and United Nations Population Fund (UNFPA) with the purpose of providing treatment and rehabilitation facilities to fistula patients and to reduce the incidence of the disease burden by conducting awareness programs and skill learning workshops all over the country. On admission, comprehensive history was taken and physical examination was performed. The diagnostic work up involved dye test in most of the cases and intra venous urography in selected cases.All confirmed cases of urinary fistula were included in the study while cases of stress and urge incontinence were excluded. Apre-designed proforma was used to gather demographic details, cause, and duration of fistula, medical and social morbidity. While for assessment of psychological morbidity, Glasgow depression scale was used after conversion into local language. Data was analyzed by SPSS version 12 to calculate mean, standard deviation, frequency and percentages.

\section{RESULTS}

During the study period among 16759 gynecological admissions, 520 were confirmed cases of urinary fistulae. Average age of patients was $31 \pm 2.8$ years and average parity was $3 \pm 2.4$. The frequency of iatrogenic fistula $(64.5 \%)$ was found to be higher than obstetrical (35.5\%) [Figure-1].

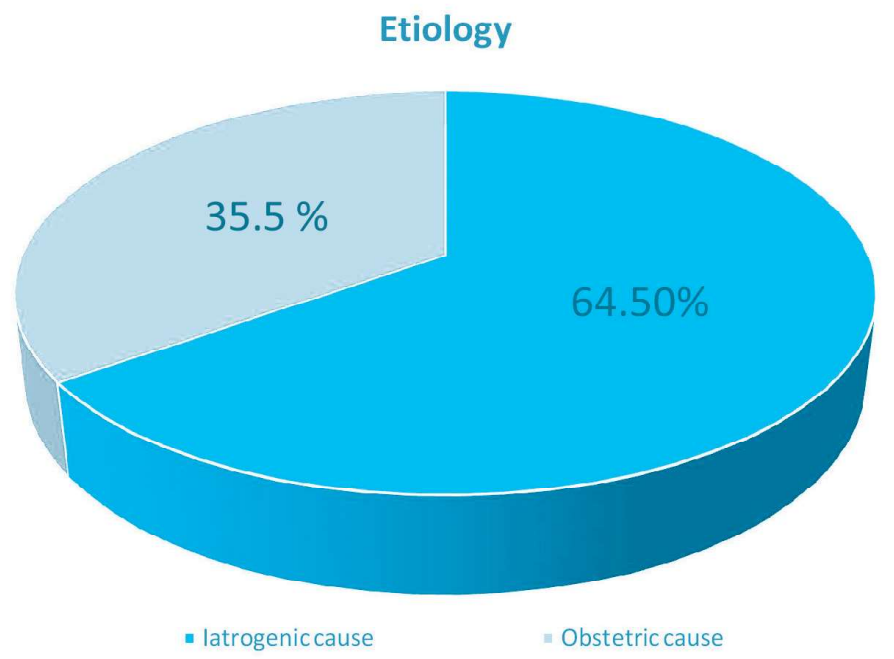

Figure 1. Etiology of vesico-vaginal fistulae $(\mathbf{n}=520)$.

Most of them ( $n=458,88 \%$ ) were malnourished while severe excoriation of vulva and inner thighs were seen in $65 \%(n=338)$ patients. Vaginal stenosis, vaginal and vesical calculi were other medical problems [Table-1]. 
Table 1: Health problems in vesico-vaginal fistulae patients $(n=520)$.

\begin{tabular}{l|l|l}
\hline \multicolumn{1}{c|}{ Health problems } & \multicolumn{1}{c|}{ No of cases } & \multicolumn{1}{c}{ Percentage } \\
\hline Local excoriation & 457 & 88 \\
\hline Mal nutrition & 338 & 65 \\
\hline Loss of fertility & 223 & 42 \\
\hline Vesical calculi & 25 & 4.8 \\
\hline Vaginal stenosis & 22 & 4.2 \\
\hline
\end{tabular}

Regarding psycho-social morbidity, major degree depression was seen in all patients while $98 \%$ were found to be socially isolated. Restriction to home with avoidance of family gatherings and travelling was seen in $62 \%$ of cases. Divorce or marriage breakdown was found in $81 \%$ of patients. $90 \%$ patients quit their job either by themselves or were kicked off. Majority (48\%) were victims of verbal abusefollowed by social and physical abuse [Table-2].

Table 2: Psycho-social morbidity in vesico-vaginal fistulae patients $(n=520)$.

\begin{tabular}{l|l|l}
\hline Psycho social morbidity & No of cases & Percentage \\
\hline Depression & 520 & 100 \\
\hline Job termination & 468 & 90 \\
\hline Marital disharmony & 421 & 81 \\
\hline Unable to perform religious activity & 379 & 73 \\
\hline $\begin{array}{l}\text { Self-avoidance/shunned from social } \\
\text { gatherings }\end{array}$ & 322 & 62 \\
\hline Verbal abuse & 249 & 48 \\
\hline Physical abuse & 151 & 29 \\
\hline
\end{tabular}

\section{DISCUSSION}

Current study found vesico-vaginal fistulas in 3.1\% of all gynecological admissions. Reported incidence varies worldwide from $0.5 \%$ to $1.7 \%{ }^{8}$ World Health organization (WHO) estimated in 1989 that more than 2 million girls and women around the world had this condition with additional 50,000 to 100,000 cases added each year. ${ }^{9}$ The frequency was found to be higher than previously reported $1.7 \%$ in same institute. ${ }^{10}$ This rise can be related to more focused fistula awareness campaigns under fistula project. Majority of the obstetric fistulas were found having time lapse of more than 5 years before reaching for definite treatment, and most of them had fistula in teens or early twenties. Their quality of life was seriously jeopardized by marital disharmony, and loss of social events at the peak age of enjoyment. This, coupled with loss of baby or having a mentally retarded baby secondary to birth asphyxia, added the psychological trauma. Cookin his study, found fistula as a devastating illness leading to marriage breakdown and isolation from families and communities. $\mathrm{He}$ attributed poverty, absent or inaccessible remedial prenatal services as the main culprit for occurrence of obstetric fistula in resource poor countries. ${ }^{11}$ In our country, poverty, illiteracy, trend of teen age marriages super imposed with social myths, lack of women empowerment about her own health and poor functioning health unit chains have made obstructed labor a common event victimizing young women. Efforts are needed to re-structure the health services to promote health education with involvements of family peers and community.

We found depression in all patients. Those patients who had recently developed fistula were less depressed in comparisonto oldand failed repaired cases of fistula. Main factors leading to depression were sense of uncleanness due to constant soakage of urine, negative behavior of husband, family in law and community and inability to perform religious activities. Mselle highlighted the importance of religious leader support of fistulae victim to relieve their depression. ${ }^{12}$ Another study from Africa shared their experience about community behavior towards fistulae victim. According to their experience, women with fistulae are valued less due to their in capability to carry out social roles. ${ }^{13}$ Weston et al reported depression, loneliness and suicidal tendency 
in fistulae victim. They found depression more severe in patients older than 20 years with unemployment and lack of social support. Almost half of the patients in their study lost their social network. ${ }^{14}$ Kabir et al reported that half of their patients felt bitter about the condition. They observed less moral and practical support by husband and family in those patients admitted for fistula repair. ${ }^{15}$ In our country, mental health is not being much incorporated in the management of patient and such facilities are not widely available in clinical settings. This issue is even more important while dealing patients with fistula whose hearts are already filled with grief. It is of utmost necessity to provide psychological support for such patients by experienced psychotherapist however at the minimum the tender loving care of family and community can help the woman to fight her illness. A study from Tanzania found high level of social support from family members and partners that enhanced recovery of patients from the terrible illness of fistula. ${ }^{16}$ This can only be achieved by intense counseling of spouse as well as family to motivate the woman for treatment and cope the illness and such strategy should be focused at priority while managing fistula patient.

Malnutrition was seen in $88 \%$ of cases. Depression along with negative behavior of family poses the women towards reduced dietary intake. Luwamand Cook identified mal- nourishment as a risk factor for fistula. ${ }^{11,17}$ Denial of family support, and aggravation of poverty worsens the dietary intake. This not only affects the quality of life of woman but also delays the surgical treatment. Atif emphasized the importance of correction of nutrition and anemia prior to treatment as a key to successful repair. ${ }^{18}$ Marked local excoriation and dermatitis was seen in $65 \%$ of cases. Quite a few had been prescribed withlocal emollients or incontinent pads. Once urinary fistula develops, the terrible consequences of urinary leakage can be reduced by wearing incontinent pads and barrier creams till definite repair. ${ }^{15}$ However, since most of these patients belong to poor socio economic group, majority cannot afford. Our department is working with the Pakistan national forum and UNFPAunder fistula project for free treatment provision. As soon as a patient is registered with confirmed fistula such treatment is given till definite management. Never the less, many of these patients cannot approach such free treatment facilities due to poverty and lack of transport facilities. It is important to address the issues of free provision of incontinent pads, barrier creams at all government health centers.

Majority of patient faced negative social behaviors and had been blamed for their illness often leading to domestic violence, marital disharmony and marriage breakdown. Not only these patients are physically abused, they also became the victim of verbal abuse. Most of the patients were socially out casted by family or had self-avoidance. David et al ${ }^{1}$ found marriage breakdown more in child-less in comparison to those with living children. Travel in public transport was also found to be a big issue, a few of the patients were off loaded early in journey. Kabir et a ${ }^{15}$ identified serious medical and social consequences of urinary fistula and emphasized the need to design and implement the strategy according to specific needs of fistulae victim. A trend of increasing rate of iatrogenic fistula has been observed rising from $18 \%$ in last decade to $26 \%$ in 2017. There was not only significant increase in the number of iatrogenic fistula after hysterectomy for gynecological conditions, but also the frequency of iatrogenic obstetrical fistula after caesarean sections and caesarean hysterectomies for placenta accreta has increased. The number was found to behigher in the remote areas of Sindh where there is lack of expertise, as well as high malpractices by unskilled surgeons. Once there is formation of urological fistula, delay in referral was seen in more than $50 \%$ of cases. There is dire need to address about the rise of iatrogenic fistula by promoting skills and arranging refresher courses.

\section{CONCLUSIONS}

Urogenital fistula is still a persistent problem in low resource countries. Patients with urogenital fistulae are not only having the surgical morbidity but they do suffer significant medical and social morbidity. There is a definite need to address these under looked miseries by a devoted fistulae team work in collaboration with social workers, religious leaders and healthcare providers to improve the quality of life of these neglected and miserable. 